\title{
Insufficient adaptive capability of pancreatic endocrine function in dexamethasone-treated ageing rats
}

\author{
M Novelli, V De Tata, M Bombara, A Lorenzini, M Masini, \\ M Pollera, E Bergamini and $\mathbf{P}$ Masiello \\ Institute of General Pathology, University of Pisa Medical School, Pisa, Italy \\ (Requests for offprints should be addressed to P Masiello, Istituto di Patologia Generale, Università degli Studi di Pisa, via Roma, 55-Scuola Medica, \\ 56126 Pisa, Italy)
}

\begin{abstract}
This study was aimed at exploring the capability of the pancreatic endocrine adaptive mechanisms of ageing Sprague-Dawley rats to counteract the metabolic challenge induced by the prolonged administration of dexamethasone (DEX) (0.13 mg/kg per day for 13 days). DEX treatment induced peripheral insulin resistance in 3-, 18- and 26-month-old rats, as indicated by the significant and persistent rise of plasma insulin levels in each age group (plasma insulin in 3-, 18- and 26-monthold rats from basal values of $4 \cdot 3 \pm 0 \cdot 8,4 \cdot 7 \pm 0.5$ and $5 \cdot 6 \pm 1 \cdot 0 \mathrm{ng} / \mathrm{ml}$ (means \pm s.E.M.) respectively, rose to $11 \cdot 9 \pm 1 \cdot 7,29 \cdot 1 \pm 5 \cdot 5$ and $27 \cdot 9 \pm 2 \cdot 7 \mathrm{ng} / \mathrm{ml}$ respectively, after 9 days of administration). However, plasma glucose concentrations remained unchanged during the treatment in young rats, whereas they increased up to frankly diabetic levels in most 18-month-old and in all 26-monthold animals after a few days of DEX administration. Plasma free fatty acid concentrations increased 2-fold in 3- and 26-month-old rats and 4-fold in 18-month-old rats and could possibly be involved in the glucocorticoid-induced
\end{abstract}

enhancement in insulin resistance, although they showed no significant correlation with glycaemic values.

Incubation of pancreatic islets obtained from treated rats showed that DEX administration increased the insulin responsiveness of islets from not only younger but also older donors. However, in the islets of ageing rats, which already showed an age-dependent impairment of the sensitivity to glucose and other secretagogues, this enhancing effect was clearly attenuated with respect to the younger counterpart. Furthermore, DEX treatment depressed significantly the priming effect of glucose in islets isolated from all the three age groups.

In conclusion, our results show that ageing rats are unable to counteract effectively a prolonged hyperglycaemic challenge as such induced by DEX administration. This homeostatic defect can be ascribed to the age-dependent failure of the endocrine pancreas to provide enough insulin to overcome the aggravation of an antecedent state of increased peripheral insulin resistance. Journal of Endocrinology (1999) 162, 425-432

\section{Introduction}

An age-related alteration of carbohydrate tolerance has been recognized for many years in both humans and rats (De Fronzo 1981, Jackson 1990), but the mechanisms involved have not been fully clarified. Several in vitro studies have indicated an impairment in insulin secretion with advancing age, since isolated islets from older rats do not release insulin as rapidly and efficiently as do islets from younger rats (Reaven et al. 1979, Sartin et al. 1986), despite partial compensation due to the development of islet hypertrophy and/or hyperplasia (Reaven et al. 1979, Coordt et al. 1995). On the other hand, studies in intact animals and man have generally shown that circulating insulin levels are either unchanged or even increased after a glucose challenge in senescence (Palmer \& Ensinck 1975, De Fronzo 1979). Moreover, studies utilizing the euglycaemic clamp technique (De Fronzo 1979, Fink et al.
1983, Jackson 1990) indicate that the age-related impairment in glucose disposal may be in large part dependent on the development of peripheral insulin resistance.

Taking into account these results, the present study aimed at exploring whether in aged rats the adaptive mechanisms of pancreatic $\beta$-cells could counteract the effects of an additional stimulus leading to increased insulin resistance, such as that induced by glucocorticoid treatment (McMahon et al. 1988, Weinstein et al. 1995). Furthermore, since glucocorticoids are antagonists of insulin effects on peripheral tissues, including fat, and recently the participation of lipid disregulation in the development of hyperglycaemia in non-insulin dependent diabetes mellitus has been emphasized (Reaven 1995, Unger 1995), we explored also the changes in plasma free fatty acid (FFA) levels of dexamethasone (DEX)-treated rats looking for a possible correlation with glycaemic values. 
Finally, we have investigated the effects of the in vivo dexamethasone administration on the response of isolated islets to glucose and other secretagogues, in order to compare the in vitro functional performances of $\beta$-cells from young and old treated animals.

\section{Materials and Methods}

Animals

Experiments were performed on three groups of male Sprague-Dawley rats of 3,18 and 26 months of age. Animals had free access to food, were kept at $24-25^{\circ} \mathrm{C}$ and with $12 \mathrm{~h}$ light: $12 \mathrm{~h}$ darkness. The Principles of Laboratory Animal Care (US NIH publication No. 83-25, revised 1985) was followed as well as the recommendations of Italian law for the use of experimental animals (DL No. 116/1992).

\section{Dexamethasone treatment}

Rats of each age-group were randomly divided into two subgroups, dexamethasone-treated and controls, which were subjected to a daily s.c. injection of either dexamethasone phosphate $(0 \cdot 125 \mathrm{mg} / \mathrm{kg}$ body weight, dissolved in saline) or saline alone respectively, for 13 days. Blood samples were collected from the tail vein of conscious animals just before and 4,9 and 13 days after the glucocorticoid treatment.

\section{Insulin extraction from the pancreas}

The day following the last dexamethasone administration, rats were anaesthetized with $50 \mathrm{mg} / \mathrm{kg}$ Nembutal i.p., the pancreas was carefully dissected free of adipose tissue and a substantial amount (300-400 mg) was weighed and homogenized in cold acidified ethanol (150:47:3, v/v; absolute ethanol: $\mathrm{H}_{2} \mathrm{O}$ :concentrated $\mathrm{HCl}$ ) for extraction of insulin as described (Bergamini et al. 1991).

\section{Isolation of islets and incubation protocol}

The remaining pancreata from each rat of the same group were pooled and used for the isolation of the islets of Langerhans by a modification of the method of Lacy \& Kostianovsky (1967), according to the suggestions of Trueheart Burch et al. (1984) and using the same procedure in all cases. After a 60 -min preincubation period in modified Krebs-Ringer bicarbonate (KRB) buffer containing $0.5 \%$ BSA, $10 \mathrm{mM}$ Hepes $\mathrm{pH} 7 \cdot 4$, and $2 \cdot 8 \mathrm{mM}$ glucose, groups of seven to ten islets were incubated for $60 \mathrm{~min}$ at $37^{\circ} \mathrm{C}$ in a humidified atmosphere of $5 \% \mathrm{CO}_{2}$ in air, in $1 \mathrm{ml} \mathrm{KRB-Hepes} \mathrm{buffer,} \mathrm{containing} 2 \cdot 8$ or $16.7 \mathrm{mM}$ glucose, this latter alone or plus $20 \mathrm{mM}$ 2-isoketocaproic acid (2-KIC), or $1 \mathrm{mM} 3$-isobutyl-1- methyl-xanthine (IBMX). At the end of this first incubation period, the medium was removed for insulin measurement, the islets were washed and incubated for a further 60-min period in $1 \mathrm{ml}$ fresh buffer, containing the same substances as above. Then, the buffer was again collected and $1 \mathrm{ml}$ cold acidified ethanol was added to extract islet insulin content.

\section{Assays}

Plasma glucose and FFA levels were measured using commercial kits (Sclavo Diagnostics, Siena, Italy and Boehringer Mannheim Italia SpA, Milan, Italy, respectively).

Insulin was measured by RIA according to Herbert et al. (1965), using rat insulin as a standard. The sensitivity and the coefficients of variation of the RIA were as follows: detection limit $0 \cdot 13 \mathrm{ng} / \mathrm{ml}$, intraassay variation $3 \cdot 1 \%$, interassay variation $10 \cdot 2 \%$.

\section{Electron microscopy}

Soon after isolation, groups of islets of Langerhans were fixed in phosphate-buffered $2.5 \%$ glutaraldehyde, washed, post-fixed in buffered $0.1 \%$ osmium tetroxide, dehydrated and finally embedded in Poly/Bed 812 (Polisciences Europe, Eppelheim, Germany) (Sabatini et al. 1963). Sections were stained with uranyl acetate and lead citrate (Reynolds 1963) and were observed with a Zeiss 902 microscope. The procedure for electron microscopic morphometry was based on the technique of Weibel (1979).

\section{Statistical analysis}

Data are given as means \pm S.E.M. Statistical significance was evaluated by ANOVA, followed by Student's $t$-test for unpaired data to assess two by two differences, when appropriate.

\section{Results}

Body weight, pancreas weight and pancreatic insulin content

Table 1 shows the body weights, pancreas weights and insulin contents of both the whole pancreas and the isolated islets of Langerhans of the six experimental groups. The administration of DEX for 13 days caused impairment of weight gain in young rats and significant reduction of body weight in aged rats (20 and 35\% decrease versus the initial values in 18- and 26-month-old rats respectively).

Concomitantly, in each group of DEX-treated rats, there was a significant decrease of the pancreas weight, which was quantitatively more relevant in 26-month-old ( $47 \%$ reduction) than in 18 -month-old ( $22 \%$ reduction) or in young rats (29\% reduction). 
Table 1 Body weight, pancreas weight and pancreatic insulin content in 3-, 18- and 26-month-old Sprague-Dawley rats treated with DEX for 13 days. Results are means \pm S.E.M. of the number of observations indicated in parentheses. DEX was administered s.C. at a daily dose of $0 \cdot 125 \mathrm{mg} / \mathrm{kg}$

\begin{tabular}{|c|c|c|c|c|c|c|}
\hline & Treatment & $\begin{array}{l}\text { Body weig } \\
\text { (g) }\end{array}$ & & $\begin{array}{l}\text { Pancreas weight } \\
(\mathrm{mg})\end{array}$ & $\begin{array}{l}\text { Pancreas IRI content } \\
\text { (ng/mg) }\end{array}$ & $\begin{array}{l}\text { Islet IRI content } \\
\text { (ng/islet) }\end{array}$ \\
\hline & & $\begin{array}{l}\text { Before } \\
\text { treatment }\end{array}$ & $\begin{array}{l}\text { After } \\
\text { treatment }\end{array}$ & & & \\
\hline & & & & & & \\
\hline 3 & & $\begin{array}{c}257 \pm 10 \\
(9)\end{array}$ & $\begin{array}{c}347 \pm 7^{\S} \\
(9)\end{array}$ & $\begin{array}{c}1092 \pm 41 \\
(9)\end{array}$ & $\begin{array}{c}231 \pm 28 \\
(9)\end{array}$ & $\begin{array}{c}122 \pm 6 \\
(35)\end{array}$ \\
\hline 18 & & $\begin{array}{c}696 \pm 26 \\
(7)\end{array}$ & $\begin{array}{c}710 \pm 19 \\
(7)\end{array}$ & $\begin{array}{c}1541 \pm 94 \\
(7)\end{array}$ & $\begin{array}{c}151 \pm 25 \\
(7)\end{array}$ & $\begin{array}{c}126 \pm 8 \\
(35)\end{array}$ \\
\hline & DEX & $\begin{array}{c}731 \pm 23 \\
(7)\end{array}$ & $\begin{array}{l}584 \pm 18^{\S *} \\
\quad(7)\end{array}$ & $\begin{array}{c}1202 \pm 41^{*} \\
\text { (7) }\end{array}$ & $\begin{array}{c}166 \pm 44 \\
(7)\end{array}$ & $\begin{array}{c}128 \pm 7 \\
(35)\end{array}$ \\
\hline 26 & Controls & $\begin{array}{c}626 \pm 44 \\
(4)\end{array}$ & $\begin{array}{c}593 \pm 49 \\
(4)\end{array}$ & $\begin{array}{c}1445 \pm 159 \\
(4)\end{array}$ & $\begin{array}{c}273 \pm 45 \\
\quad(4)\end{array}$ & $\begin{array}{c}209 \pm 12 \\
(35)\end{array}$ \\
\hline
\end{tabular}

${ }^{s_{P}} P<0 \cdot 01$ versus the initial body weight; ${ }^{*} P<0 \cdot 05$, at least, versus the corresponding controls (unpaired Student's $t$-test).

On the other hand, DEX treatment significantly increased the pancreatic insulin content in the young animals only, and the islet insulin content in both 3 - and 26-month-old rats $(P<0 \cdot 01)$.

Electron microscopic morphometry showed no difference between islets isolated from control and DEX-treated rats of each age-group with regard to organelles structure and degree of granulation (data not shown).

\section{Plasma glucose and insulin levels}

Figure 1 shows the variations of plasma glucose and insulin levels after 0, 4, 9 and 13 days of treatment with DEX. In all the untreated control groups neither plasma glucose nor insulin levels changed significantly during the experimental period. Plasma glucose levels were not modified by the treatment in 3-month-old rats, whereas 18- and 26-month-old rats developed a marked hyperglycaemia, which, for the latter group, was already significant after 4 days of DEX administration. DEX treatment, on the other hand, rapidly induced a 2-fold increase of plasma insulin levels in young rats, and a 4- to 5-fold increase in older rats. In ageing animals, the increment of both glucose and insulin plasma levels appeared to decline at the end of DEX treatment. It should be noticed that the glycaemic changes of DEX-treated 18-month-old rats were not homogeneous, since three animals out of seven remained normoglycaemic throughout the experiment, whereas the others attained plasma glucose values in the range $375-445 \mathrm{mg} / 100 \mathrm{ml}$ at the end of the treatment. Independently of glycaemia, all these rats showed a marked hyperinsulinaemia. An interesting positive correlation was found in 18-month-old treated rats between the initial body weight and post-treatment either glycaemic or insulinaemic values $(r=0.802$ and 0.864 respectively, $P<0 \cdot 05)$.

\section{Plasma FFA levels}

After 13 days of DEX administration, plasma FFA levels increased 2-fold in 3- and 26-month-old rats and 4-fold in 18-month-old animals with respect to basal values (Table 2). In the 18-month-old animal group, the remarkable increase in FFA plasma levels showed little variability and was not correlated to plasma glucose levels $(r=0 \cdot 014$, NS). This increase occurred early during DEX treatment and remained stable until the end (plasma FFA concentrations were $1274 \pm 237 \mu \mathrm{Eq} / 1$ at 4 days and $1426 \pm 160 \mu \mathrm{Eq} / 1$ at 8 days of treatment, i.e. close to the values at day 14 in Table 2).

\section{Insulin secretion from isolated islets}

Figure 2 shows the results of the stimulation by various secretagogues of the islets of Langerhans isolated from control and DEX-treated rats of 3,18 and 26 months of age. At $2.8 \mathrm{mM}$ glucose, the effect of age on basal insulin secretion (as percentage of the islet insulin content) was significant $(F=38 \cdot 7, P<0 \cdot 01)$ and influenced significantly the effect of DEX treatment $\left(F_{\text {interaction }}=10.5, P<0.01\right)$. In the islets from 18-month-old untreated rats, the insulin secretion was significantly stimulated by glucose, but, at variance with the young controls, the other secretagogues (IBMX and 2-KIC) were unable to potentiate the 
A



$\bar{E}$

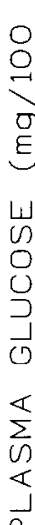

$\mathrm{a}$

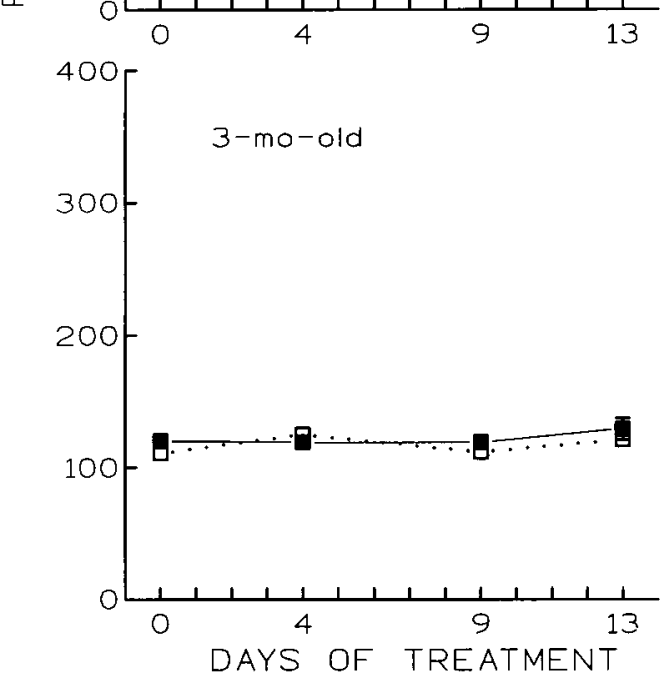

$\mathrm{B}$
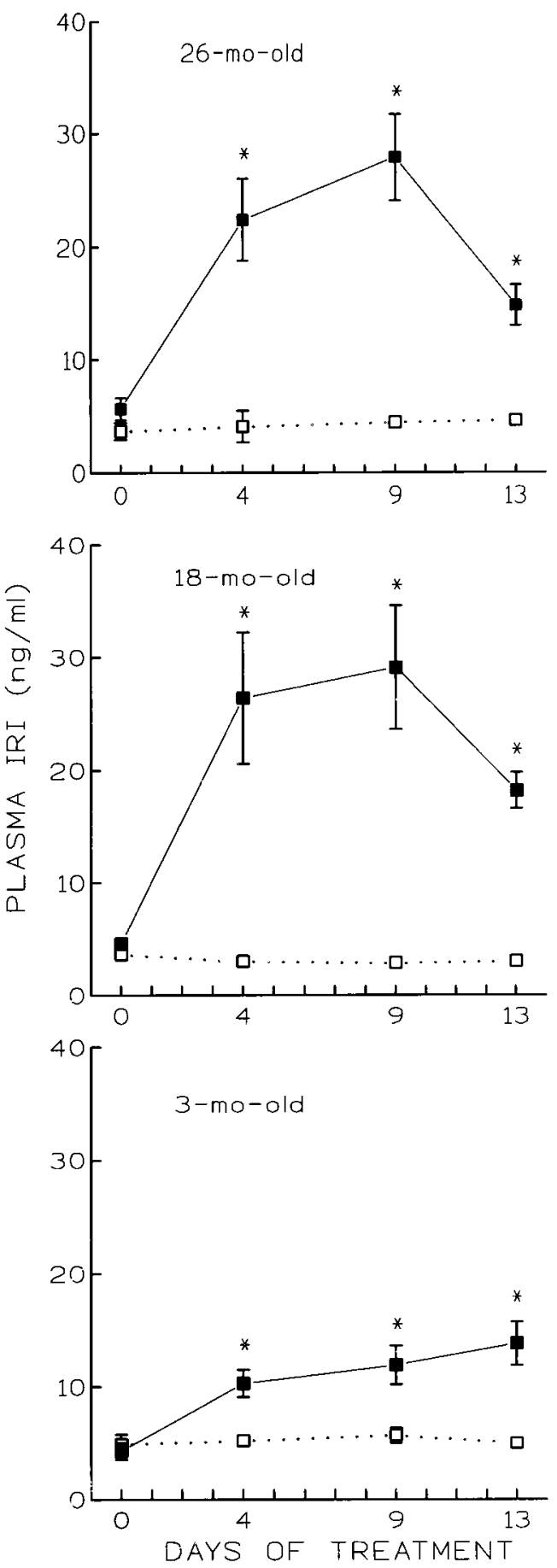

Figure 1 Plasma glucose (A) and insulin (B) concentrations in control $(\square)$ and dexamethasone-treated ( $\mathbf{\square})$ Sprague-Dawley rats of various ages. Data are expressed as means \pm S.E.M. of nine, seven and four cases for 3-, 18and 26-month-old rats, respectively. ${ }^{*} P<0 \cdot 05$, at least, versus age-matched control rats (unpaired Student's $t$-test). 
Table 2 FFA plasma levels in Sprague-Dawley rats of various ages, treated with DEX $(0 \cdot 125 \mathrm{mg} / \mathrm{kg}$ per day) for 13 days. Results are means \pm S.E.M. of the number of observations indicated in parentheses

\begin{tabular}{|c|c|c|}
\hline & FFA $(\mu \mathrm{Eq} / \mathrm{l}$ & \\
\hline & $\begin{array}{l}\text { Before } \\
\text { treatment }\end{array}$ & $\begin{array}{l}\text { After } \\
\text { treatment }\end{array}$ \\
\hline $\begin{array}{l}\text { Age } \\
\text { (months) }\end{array}$ & & \\
\hline 3 & $\begin{array}{c}410 \pm 38 \\
\text { (9) }\end{array}$ & $\begin{array}{c}799 \pm 155 \\
\text { (7) }\end{array}$ \\
\hline 18 & $\begin{array}{c}324 \pm 49 \\
\text { (7) }\end{array}$ & $\begin{array}{c}1315 \pm 137 \\
\text { (7) }\end{array}$ \\
\hline 26 & $\begin{array}{c}247 \pm 40 \\
(4)\end{array}$ & $\begin{array}{c}656 \pm 37 \\
(4)\end{array}$ \\
\hline
\end{tabular}

ANOVA showed that the effect of DEX treatment was significant $(F=56 \cdot 6$, $P<0 \cdot 01)$, as well as the effect of age $(F=7 \cdot 33, P<0 \cdot 01)$, and the interaction $(F=5 \cdot 09, P<0 \cdot 05)$.

stimulatory effect of the sugar. Finally, in the islets from the 26-month-old untreated rats, the response to all stimuli was weak. DEX treatment caused generally an increase of insulin release from the isolated islets of all age-groups in the presence of both glucose alone and glucose plus IBMX or 2-KIC: this enhancing effect was relevant in young islets and clearly attenuated in islets taken from 18and 26-month-old rats (the effect of the interaction age $\times$ DEX treatment was significant for all three stimuli). Additional experiments performed in DEX-treated 18- month-old rats showed no difference in the insulin secretory response of islets isolated from either normoglycaemic or hyperglycaemic animals (data not shown).

As reported in Table 3, the insulin release from isolated islets of young controls during the second incubation period (see Materials and Methods) was significantly enhanced by the repeated stimulation with glucose alone or glucose plus IBMX. In the case of older islets, only the combination of $16.7 \mathrm{mM}$ glucose and $1 \mathrm{mM}$ IBMX retained this ability, in agreement with previous results (Bombara et al. 1995). In the islets of DEX-treated animals of all age groups, the time-dependent potentiation of insulin release did not occur and occasionally significantly less insulin was released during the second incubation than during the first.

\section{Discussion}

One of the main results of the present study is the observation that in ageing rats, at variance with young animals, the adaptive mechanisms of the endocrine pancreas are inadequate to overcome the glucocorticoidinduced insulin resistance, so that hyperglycaemia ensues.

Our data confirm that dexamethasone-induced insulin resistance is associated with increased circulating insulin levels as a result of a compensatory response of pancreatic $\beta$-cells (Bonner-Weir et al. 1981). In our experiments, plasma insulin concentrations had already increased significantly after 4 days of treatment in all age-groups and

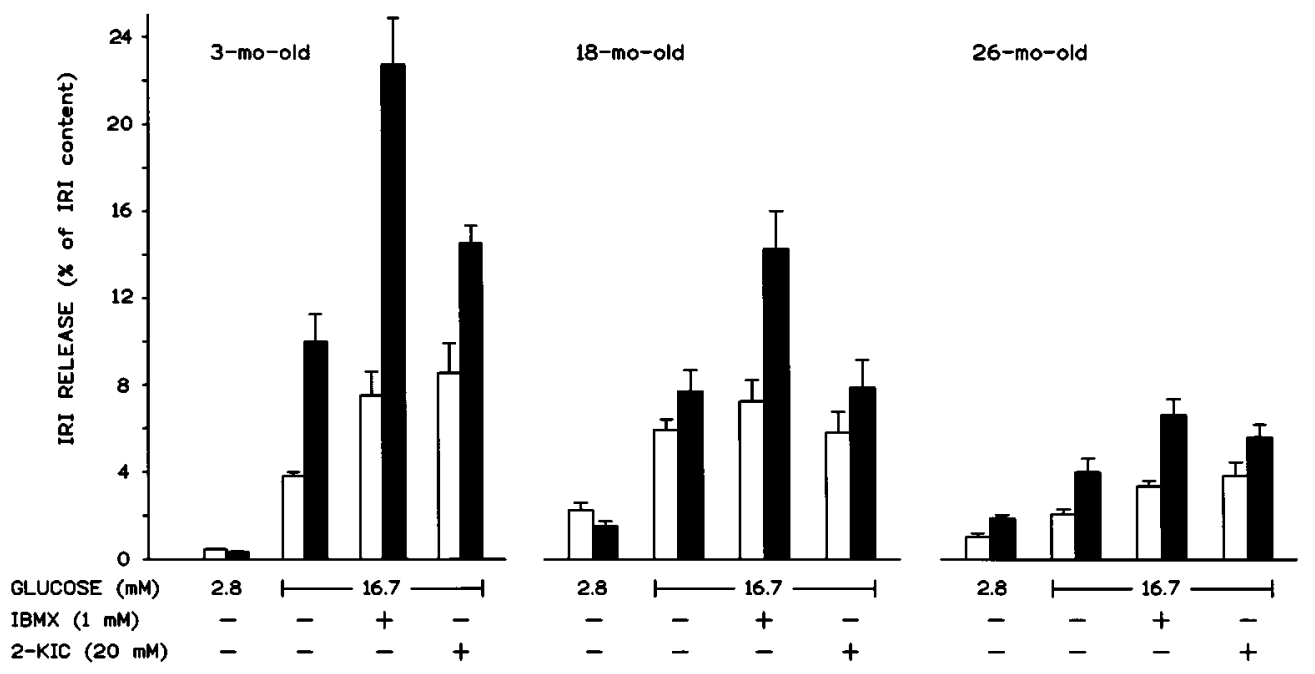

Figure 2 Insulin release from isolated islets of 3-, 18- and 26-month-old control $(\square)$ and dexamethasonetreated ( $\mathbf{\square})$ rats. Islets were incubated for $60 \mathrm{~min}$ in the presence of the indicated secretagogues. Means \pm S.E.M. of five observations. ANOVA showed that the effect of dexamethasone was significant $(P<0 \cdot 01)$ for the stimulation with $16.7 \mathrm{mM}$ glucose alone $(F=31 \cdot 6)$ or in combination with IBMX $(F=64 \cdot 1)$ or 2-KIC $(F=20 \cdot 1)$; the effect of age was significant $(P<0 \cdot 01)$ for all the incubation conditions $(F=38 \cdot 7 ; F=24 \cdot 5$; $F=30 \cdot 4 ; F=27 \cdot 4$; for $2.8 \mathrm{mM}$ glucose, $16.7 \mathrm{mM}$ glucose alone or in combination with IBMX or 2-KIC, respectively); the interaction was also significant $(P<0.05$ at least) in all cases $(F=10 \cdot 5 ; F=6 \cdot 11 ; F=11 \cdot 0$; $F=4 \cdot 11$; respectively). 
Table 3 Insulin release from isolated islets of control and DEX-treated rats of various ages during the second 60-min incubation period in the presence of the indicated stimuli. Results are means \pm S.E.M. of four or five incubations for each group of islets. To facilitate comparisons between 1st and 2nd incubation, changes versus 1st incubation are also indicated

\begin{tabular}{|c|c|c|c|c|c|}
\hline & \multirow{2}{*}{ Treatment } & \multicolumn{2}{|l|}{$16.7 \mathrm{mM}$ glucose } & \multicolumn{2}{|c|}{ 16.7 mM glucose + $1 \mathrm{mM}$ IBMX } \\
\hline & & $\begin{array}{l}\text { IRI release during } \\
2 \text { nd incubation } \\
\text { (\% of IRI content) }\end{array}$ & $\begin{array}{l}\text { Changes vs } 1 \text { st } \\
\text { incubation } \\
(\%)\end{array}$ & $\begin{array}{l}\text { IRI release during } \\
2 \text { nd incubation } \\
\text { (\% of IRI content) }\end{array}$ & $\begin{array}{l}\text { Changes vs } 1 \text { st } \\
\text { incubation } \\
(\%)\end{array}$ \\
\hline \multicolumn{6}{|c|}{$\begin{array}{l}\text { Age } \\
\text { (months) }\end{array}$} \\
\hline 3 & $\begin{array}{l}\text { Control } \\
\text { DEX }\end{array}$ & $\begin{array}{l}5 \cdot 5 \pm 0 \cdot 2^{*} \\
9 \cdot 7 \pm 0 \cdot 9\end{array}$ & $\begin{array}{l}+43 \\
-0.5\end{array}$ & $\begin{array}{l}15 \cdot 7 \pm 1 \cdot 6^{*} \\
15 \cdot 6 \pm 1 \cdot 2^{*}\end{array}$ & $\begin{array}{r}+106 \\
-31\end{array}$ \\
\hline 26 & $\begin{array}{l}\text { Control } \\
\text { DEX }\end{array}$ & $\begin{array}{l}2 \cdot 3 \pm 0 \cdot 3 \\
2 \cdot 7 \pm 0 \cdot 6\end{array}$ & $\begin{array}{l}+8 \cdot 3 \\
-34\end{array}$ & $\begin{array}{l}7 \cdot 1 \pm 0 \cdot 6^{*} \\
4 \cdot 7 \pm 0 \cdot 7\end{array}$ & $\begin{array}{r}+112 \\
-30\end{array}$ \\
\hline
\end{tabular}

${ }^{*} P<0.05$ (at least) versus the corresponding values of the 1 st incubation period (Fig. 2).

remained high on the following days. However, whereas a moderate hyperinsulinaemia is sufficient to prevent any increase in plasma glucose levels in young rats, even a remarkable increase in circulating insulin appears inadequate to maintain normoglycaemia in most of older animals. Our results point out that the age of 18 months may be critical for the development of the age-related failure of the adaptive mechanisms regulating glucose homeostasis. In fact, differently from 26-month-old rats which became all markedly hyperglycaemic following DEX administration, in the 18-month-old group, three out of seven animals remained normoglycaemic throughout the treatment. Apparently, this discrepancy was due to differences neither in insulin secretory response nor in lipid disregulation, since circulating insulin and FFA levels increased similarly in both hyper- and normoglycaemic animals of this age-group. It is worth noticing that our results confirm that the antilipolytic effect of insulin is blunted by DEX treatment (Venkatesan et al. 1996).

The present study clearly indicates that the variable effects of glucocorticoid treatment on blood glucose concentrations are not only genetically determined as suggested by Ogawa et al. (1992), but also dependent on acquired factors such as age, overweight or both. Taking into account the hypothetical involvement of abundant lipid availability in the pathogenesis of hyperglycaemia in insulin resistant states such as obesity (Unger 1995), it is possible that the elevation of blood glucose in older rats could be mediated, at least in part, by the DEX-induced rise in circulating FFA levels, which interferes with glucose uptake and utilization particularly in muscles (Venkatesan et al. 1987, Groop et al. 1991, Roden et al. 1996). However, besides the reported failure of inhibitors of FFA oxidation in improving muscle glucose uptake (Venkatesan et al. 1996), it should be stressed that in our study the putative unfavourable effect of elevated plasma
FFA levels occurred only in rats which were likely to be already insulin resistant because of advanced age and/or overweight. Indeed, it is of interest that DEX-treated 26-month-old rats became hyperglycaemic despite a modest increase in FFA circulating levels and that in 18-month-old animals post-treatment glucose levels were positively correlated with the initial body weight, but not with plasma FFA concentrations.

Glucocorticoid-induced insulin resistance is usually associated with a compensatory increase in $\beta$-cell mass (Ogawa et al. 1992) and pancreatic insulin content (Bonner-Weir et al. 1981). Our data on pancreatic and islet insulin stores fully confirm this latter observation for DEX-treated young rats only.

Stimulation of insulin release in isolated islets from aged untreated rats highlights a diminished responsiveness to glucose alone or in combination with other secretagogues, in agreement with previous observations (Reaven et al. 1979, Bergamini et al. 1991, Inoue et al. 1997). This reduced response was particularly remarkable in the islets from the oldest control group. However, it should be stressed that the secretory response was enhanced by DEX treatment not only in islets of young rats, in agreement with Malaisse et al. (1967) and Wang et al. (1994), but also in islets of older animals, although to a lesser extent. Therefore, despite the possibility of an adverse influence of a glucose-rich environment, a phenomenon known as glucose toxicity (Weir \& Leahy 1994), the hyperglycaemic state of the older animals in our experimental conditions does not appear to be harmful for islet function both in vivo and in vitro, at least within the time limits of our study. Nevertheless, the hypothesis that prolonged hyperglycaemia might unfavourably affect the extent of $\beta$-cell compensatory response cannot be ruled out.

The present data confirm our previous observation that the time-dependent potentiation of glucose effect (i.e. the 
enhancement of insulin secretion in response to a second glucose stimulus) is impaired in ageing animals (Bombara et al. 1995). Interestingly, DEX treatment interfered with the priming effect of glucose in the islets from all agegroups, likely as a consequence of the large insulin release from the $\beta$-cells during the first incubation. Similar results were obtained by Grill \& Rundfeldt (1986) in the perfused pancreas of DEX-treated young rats.

In conclusion, our results show that the adaptive mechanisms regulating glucose homeostasis weaken in ageing rats and become unable to efficiently counteract a metabolic hyperglycaemic challenge such as that represented by the prolonged administration of DEX. In this age-related alteration of glucose homeostasis two functionally distinct aspects can be identified. On one side, the elevation of plasma glucose and FFA levels in older DEX-treated rats in spite of the concomitant increase in circulating insulin, clearly indicates a reduction of the insulin sensitivity of the peripheral tissues, which most likely is the result of the synergistic effects of DEX treatment and antecedent ageand/or weight-related alterations. On the other hand, the 'in vitro' experiments with the isolated pancreatic islets reveal an age-related impairment of the maximal secretory capabilities of $\beta$-cells, which probably makes these cells unable to provide sufficient compensation to prevent alteration of glucose homeostasis.

\section{Acknowledgements}

This work was supported by grants from the Ministero dell'Università e della Ricerca Scientifica e Tecnologica and from the C N R (Progetto Finalizzato Invecchiamento). The skillful technical assistance of $\mathrm{Mr} \mathrm{E}$ Taccini is gratefully acknowledged.

\section{References}

Bergamini E, Bombara M, Fierabracci V, Masiello P \& Novelli M 1991 Effect of different regimens of dietary restriction on the age-related decline in insulin secretory response of isolated rat pancreatic islets. Annals of the New York Academy of Science $\mathbf{6 2 1}$ 327-336.

Bombara M, Masiello P, Novelli M \& Bergamini E 1995 Impairment of the priming effect of glucose on insulin secretion from isolated islets of ageing rats. Acta Diabetologica 32 69-73.

Bonner-Weir S, Trent DF, Zmachinski CJ, Clore ET \& Weir GC 1981 Limited beta cell regeneration in a beta cell deficient rat model: studies with dexamethasone. Metabolism 9 914-918.

Coordt MC, Ruhe RC \& McDonald RB 1995 Ageing and insulin secretion. Proceedings of the Society of Experimental Biology and Medicine 209 213-222.

De Fronzo RA 1979 Glucose intolerance and aging. Evidence for tissue insensitivity to insulin. Diabetes 28 1095-1101.

De Fronzo RA 1981 Glucose intolerance and aging. Diabetes Care 4 493-501.

Fink RI, Kolterman OG, Griffin J \& Olefsky JM 1983 Mechanisms of insulin resistance in aging. Journal of Clinical Investigation $\mathbf{7 1}$ $1523-1535$.
Grill V \& Rundfeldt M 1986 Abnormalities of insulin responses after ambient and previous exposure to glucose in streptozocin-diabetic and dexamethasone-treated rats. Diabetes 35 44-51.

Groop LC, Saloranta C, Shank M, Bonadonna RC, Ferrannini E \& De Fronzo RA 1991 The role of free fatty acid metabolism in the pathogenesis of insulin resistance in obesity and noninsulindependent diabetes mellitus. Journal of Clinical Endocrinology and Metabolism 72 96-107.

Herbert V, Lau KS, Gottlieb CW \& Bleicher SJ 1965 Coated charcoal immunoassay of insulin. Journal of Clinical Endocrinology 25 $1375-1384$.

Inoue K, Norgren S, Luthman H, Moeller C \& Grill V 1997 Beta cells of aging rats: impaired stimulus-secretion coupling but normal susceptibility to adverse effects of diabetic state. Metabolism 46 242-246.

Jackson RA 1990 Mechanisms of age-related glucose intolerance. Diabetes Care 13 (Suppl 2) 9-19.

Lacy PE \& Kostianovsky M 1967 Method for the isolation of intact islets of Langerhans from the rat pancreas. Diabetes 16 35-39.

Malaisse WJ, Malaisse-Lagae F, McCraw EF \& Wright PH 1967 Insulin secretion in vitro by pancreatic tissue from normal, adrenalectomized, and cortisol-treated rats. Proceedings of the Society of Experimental Biology and Medicine 124 924-928.

McMahon M, Gerlich J \& Rizza R 1988 Effects of glucocorticoids on carbohydrate metabolism. Diabetes and Metabolism Review $\mathbf{4}$ $17-30$.

Ogawa A, Johnson JH, Ohneda M, McAllister CT, Inman L, Alan T \& Unger RH 1992 Roles of insulin resistance and beta-cell disfunction in dexamethasone-induced diabetes. Journal of Clinical Investigation 90 497-504.

Palmer JP \& Ensinck JW 1975 Acute-phase insulin secretion and glucose tolerance in young and aged normal men and diabetic patients. Journal of Clinical Endocrinology and Metabolism $\mathbf{4 1}$ 498-503.

Reaven EP, Gold G \& Reaven GM 1979 Effect of age on glucosestimulated insulin release by the beta-cell of the rat. Journal of Clinical Investigation 64 591-599.

Reaven GM 1995 The fourth Musketeer. From Alexandre Dumas to Claude Bernard. Diabetologia 38 3-13.

Reynolds ES 1963 The use of lead citrate at high $\mathrm{pH}$ and an electron opaque stain in electron microscopy. Journal of Cell Biology 17 208-212.

Roden M, Price TB, Perseghin G, Petersen KF, Rothman DL \& Cline GW 1996 Mechanism of free fatty acid-induced insulin resistance in humans. Journal of Clinical Investigation 97 2859-2865.

Sabatini DD, Bensch K \& Barnett RJ 1963 Cytochemistry and electron microscopy. The preservation of cellular ultrastructure and enzymatic activity by aldehyde fixation. Journal of Cell Biology 17 $19-58$.

Sartin JL, Chaudhuri M, Farina S \& Adelman RC 1986 Regulation of insulin secretion by glucose during aging. Journal of Gerontology $\mathbf{4 1}$ $30-35$.

Trueheart Burch P, Berner DK, Leontire A, Vogin A, Matschinsky BM \& Matschinsky FM 1984 Metabolic adaption of pancreatic islet tissue in aging rats. Journal of Gerontology $392-6$.

Unger RH 1995 Lipotoxicity in the pathogenesis of obesity-dependent NIDDM. Diabetes 44 863-870.

Venkatesan N, Davidson MB \& Hutchinson A 1987 Possible role for the glucose-fatty acid cycle in dexamethasone-induced insulin antagonism in rats. Metabolism 36 883-891.

Venkatesan N, Lim J, Bouch C, Marciano D \& Davidson MB 1996 Dexamethasone-induced impairment in skeletal muscle glucose transport is not reversed by inhibition of free fatty acid oxidation. Metabolism 45 92-100.

Wang Z-L, Bennet WM, Wang R-M, Ghatei MA \& Bloom SR 1994 Evidence of a paracrine role of neuropeptide $\mathrm{Y}$ in the 
regulation of insulin release from pancreatic islets of normal and dexamethasone-treated rats. Endocrinology 135 200-206.

Weibel ER 1979 Stereological methods. In Practical methods for biological morphometry, edn 3, vol 1, pp 1-415. London: Academic Press Limited.

Weinstein SP, Paquin A, Pritsker A \& Haber RS 1995 Glucocorticoidsinduced insulin resistance: dexamethasone inhibits the activation of glucose transport in rat skeletal muscle by both insulin- and non-insulin-related stimuli. Diabetes 44 441-445.
Weir GC \& Leahy JL 1994 Pathogenesis of non insulin-dependent (type II) diabetes mellitus. In Joslin's Diabetes Mellitus, edn 13, pp 240-264. Eds CR Kahn \& GR Weir. Philadelphia: Lea and Febiger.

Received 26 January 1999

Revised manuscript received 13 April 1999

Accepted 26 April 1999 